\title{
LETRAMENTO RACIAL MEDIADO PELA LITERATURA INFANTO- JUVENIL NA EDUCAÇÃO BÁSICA
}

\section{RACIAL LITERACY MEDIATED BY LITERATURE CHILDREN IN BASIC EDUCATION}

\author{
Eduardo Dias da Silva ${ }^{1}$ \\ Romar Souza-Dias ${ }^{2}$
}

\begin{abstract}
Resumo: Este artigo, elaborado a partir de pesquisa transdisciplinar qualitativa de modalidade exploratória, traz a perspectiva do letramento racial mediado pela literatura infanto-juvenil no empoderamento das histórias e culturas africana, afro-brasileira e indígena de forma críticoreflexivo em ambientes escolares da educação básica pública. Professores deparam-se com a falta de instrumentos pedagógicos e práticos no desenvolvimento de estratégias para melhor exercerem a atividades de conscientização das várias identidades étnico-raciais que formam o mosaico cultural do Brasil. Objetivamos responder ao seguinte questionamento: o letramento racial mediado pela Literatura Infanto-juvenil, para aprendentes da educação básica, pode contribuir de que maneira para a implementação do ensino da história e da cultura afrobrasileira, africana e indígena nas escolas públicas? Através desse trabalho, fizemos uma sugestão, dentre vários títulos possíveis, de alguns livros que tratam dessa temática, contudo ressaltamos que esse artigo não se limita às ideias de tarefas, mas se perpetua como caminho para novas reflexões na construção social na qual ninguém tenha que negar ou apagar sua identidade étnico-racial.
\end{abstract}

Palavras-chave: Letramento racial; Histórias e culturas africana, afro-brasileira e indígena; Literatura infanto-juvenil; Educação básica.

Abstract: This article, whose written is based on an exploratory, qualitative and transdisciplinary research brings the perspective of racial literacy mediated by children's literature in the empowerment of African, African-Brazilian and Indigenous histories and cultures in a reflective and critical way in school environments of public and basic education. Teachers are confronted with the lack of educational and practical tools to develop strategies to better pursue the awareness-raising activities of various ethnic and racial identities that make up the cultural mosaic of Brazil. In this paper, we aim to answer the following question: in which way racial literacy mediated by children Literature for learners of basic education can contribute to implement the teaching of African-Brazilian, African and Indigenous history and culture in public schools? Based on this investigation, among several possible titles, we made a suggestion of some books that address the issue of ethnic and racial identities; however, we stress that this article is not limited to the task ideas, but it

\footnotetext{
${ }^{1}$ Doutorando em Literatura e Mestre em Linguística Aplicada pela Universidade de Brasília (UnB). Professor de LEM/Francês e Pedagogo na Educação Básica da Secretaria de Estado de Educação do Distrito Federal (SEEDF). Pesquisador dos Grupos CNPq GECAL/UnB, FORPROLL/UFVJM e GIEL/UFLA. Contato: edu_france2004@yahoo.fr

${ }^{2}$ Doutorando em Linguística pela Universidade de Brasília - UnB. Mestre em Linguística Aplicada pela Universidade de Brasília - UnB. Professor Assistente da Universidade do Estado da Bahia - UNEB, Campus VI. Contato: rogabam@yahoo.com.br
} 
perpetuates as a path to new thinking in the social construction in which no one has to deny his/her ethno-racial identity neither has it erased.

Keywords: Racial literacy; Histories and cultures african, african-brazilian and indigenous; Children's literature; Basic education.

\section{Introdução}

Este artigo transdisciplinar, oriundo de uma pesquisa exploratória (Almeida, 1996; Gil, 1993; Marconi; Lakatos, 1990), objetiva indicar rumos, levantar possibilidades e favorecer discussões acerca do letramento racial mediado pela Literatura infanto-juvenil na educação básica nas escolas públicas brasileiras. Inspirados pelas leis federais 10.639/03 e 11.645/08 sobre o ensino de histórias e culturas africana, afro-brasileira e indígena, pelas ideias advindas das teorias de novos letramentos e multiletramentos (Cope; Kalantziz, 2000; Lankshear; Knobel, 2003; Rojo; Moura, 2013; Street, 2014; Rocha, 2012), Literatura infanto-juvenil (Abramovich, 1997; Aguiar et al, 1982; Arroyo, 1990; Coelho, 2000; 2002; Sousa, 2005), leitura e a prática (Lajolo, 2008; Lajolo; Zilberman, 1999; Martins, 2006; Zilberman, 2003) veem, nesse contexto, constituir proposta pedagógica capaz de indicar alternativas para a (re)construção da identidade racial dos aprendentes ${ }^{3}$ e dos professores que se quer cidadãos-críticos conscientes de seus direitos e deveres nesse caleidoscópio racial que é o Brasil, segundo Silva (2015).

Os professores, atores sociais, já chegam ao ambiente escolar com um conhecimento de mundo bem amplo, na maioria das vezes. Entendemos que compete a esses e ao estabelecimento de ensino sistematizar esses dados com propostas pedagógicas e metodologia que atendam às necessidades específicas em relação à apropriação do ensino da história e da cultura afro-

\footnotetext{
${ }^{3}$ Optamos nesta pesquisa pelo uso do termo aprendente(s) ao nos referir ao sujeito que aprende, pois consideramos a aprendizagem uma construção individual e interna, realizandose num processo histórico, pessoal e social,dentro de um corpo investido de significação simbólica. Tendo as experiências, as relações e as percepções do mundo no qual foram inseridos serão significativas na construção do seu sistema cognitivo, social e afetivo e em seu desenvolvimento, como elucidado por Silva (2014).
} 
brasileira, africana e indígena numa perspectiva transdisciplinar via letramento racial mediado pela literatura infanto-juvenil para os aprendentes da educação básica pública.

Devemos esclarecer que o presente artigo se insere na tendência transdisciplinar que vem marcando as pesquisas em Educação, Linguística, Linguística Aplicada (Crítica), dentre outras áreas, nos últimos anos, ao trazer o entendimento de que "a transdisciplinaridade diz respeito ao estudo de um objeto de uma mesma e única disciplina por várias disciplinas ao mesmo tempo", segundo Vieira (2009, p. 8).

Assim, por meio dos resultados desse trabalho, almejamos apontar a importância de se fornecerem oportunidades de formação continuada para que os professores da educação básica pública possam, através do letramento racial, conhecer, refletir e discutir suas ações e metodologias para o ensino da história e da cultura afro-brasileira, africana e indígena mediadas pelas Literatura Infanto-juvenil. E não se pretende, em hipótese alguma, exaurir todas as possibilidades de pesquisa que envolvem as temáticas supracitadas.

Objetivamos responder ao seguinte questionamento: o letramento racial mediado pela Literatura Infanto-juvenil, para aprendentes da educação básica, pode contribuir de que maneira para a implementação do ensino da história e da cultura afro-brasileira, africana e indígena nas escolas públicas?

Visando alcançar o objetivo proposto foi feita pesquisa exploratória, com vistas a proporcionar maior familiaridade com os problemas referentes à formação continuada de docentes da educação básica para o ensino da história e da cultura afro-brasileira, africana e indígena nas escolas públicas através da implementação de atividades de incentivo às temáticas em tela dentro do ambiente escolar, proporcionando maior visibilidade ao assunto. Este tipo de pesquisa foi adotado, pois "é o que mais aprofunda o conhecimento da realidade, porque explica a razão, o porquê das coisas" (Gil, 1993, p.46). 
A pesquisa exploratória "apresenta descrições fidedignas de uma situação, tentando descobrir as relações existentes entre seus elementos" (Almeida, 1996, p.105). Gil ainda esclarece que a pesquisa exploratória, na maioria dos casos, envolve "levantamento bibliográfico [e] pessoas que tiveram experiências práticas com o problema pesquisado" (1993, p. 45).

Dessa forma, com base nos procedimentos técnicos a serem utilizados foi realizada também uma pesquisa bibliográfica. Esta, conforme esclarece Gil, "é desenvolvida com base em material já elaborado constituído principalmente de livros e artigos científicos" (1993, p. 48), ou seja, complementando a ideia com outros autores, "é um apanhado geral sobre os principais trabalhos já realizados" (Marconi; Lakatos, 1990, p. 23).

Essa pesquisa possui abordagem qualitativa, pois os dados colhidos são compostos, em sua grande maioria, por relatos de profissionais que trabalham com formação continuada e o ensino da história e da cultura afrobrasileira, africana e indígena. A pesquisa qualitativa é baseada "na presença ou ausência de alguma qualidade ou característica, e também na classificação de tipos diferentes de dadas propriedades" (Marconi \& Lakatos, 1990, p.126).

Consideramos que os temas tratados nesse artigo são relevantes porque as possibilidades que a formação continuada para professores da educação básica através de metodologias e práticas para o ensino da história e da cultura afro-brasileira, africana e indígena suscitadas por essa pesquisa são fundamentais para o desenvolvimento dos aprendentes, professores e da sociedade em geral.

\section{Letramento(s)}

Letrar é mais que alfabetizar, é ensinar a ler e escrever dentro de um contexto onde a escrita e a leitura tenham sentido e façam parte da vida dos aprendentes dentro e fora do ambiente escolar, de acordo com Rojo (2009) e Silva (2016). 
O termo letramento pode ser considerado bastante atual no campo da educação brasileira. Conforme Soares (2009, p. 33), esse termo parece ter sido usado pela primeira vez no país por Kato, no livro No mundo da escrita: uma perspectiva psicolinguística (1986). Como parte de título de livro, o termo apareceu nos livros Os significados do letramento (1995), organizado por Kleiman e Alfabetização e Letramento (2010), de Tfouni, autoras das quais nos utilizamos para embasar esse trabalho.

A busca por uma definição única para o termo letramento parece ser algo difícil, uma vez que se trata de um conceito amplo e complexo. Conforme Soares (2009),

as dificuldades e impossibilidades devem-se ao fato de que o letramento cobre uma vasta gama de conhecimentos, habilidades, capacidades, valores, usos e funções sociais; o conceito de letramento envolve, portanto, sutilezas e complexidades difíceis de serem contempladas em uma única definição (SOARES, 2009, p. 65).

Já Mortatti (2004) afirma que "até por ser uma palavra recente, nem sempre são idênticos os significados que the vêm sendo atribuídos, assim como os objetivos com que é utilizada [a palavra letramento]" (p. 11, grifo nosso). Traremos, a seguir, definições que alguns autores utilizam para esse conceito.

Refletindo sobre os significados de letramento, Tfouni (2010) sugere que não pode haver a redução do seu significado ao significado de alfabetização e ao ensino formal. Para ela letramento é um processo mais amplo que a alfabetização e que deve ser compreendido como um processo sócio-histórico. Tfouni (2010) relaciona, assim, letramento com o desenvolvimento das sociedades. Nesse sentido, a autora explica que: 
Em termos sociais mais amplos, o letramento é apontado como sendo produto do desenvolvimento do comércio, da diversificação dos meios de produção e da complexidade crescente da agricultura. Ao mesmo tempo, dentro de uma visão dialética, torna-se uma causa de transformações históricas profundas, como o aparecimento da máquina a vapor, da imprensa, do telescópio, e da sociedade industrial como um todo (TFOUNI, 2010, p. 23).

Letramento seria, portanto, causa e consequência do desenvolvimento. Assim, o significado atribuído pela autora ao termo letramento extrapola o ambiente escolar e o processo de alfabetização, referindo-se a processos sociais mais amplos.

O letramento focaliza os aspectos sócio-históricos da aquisição da escrita. [Ele] tem por objetivo investigar não somente quem é alfabetizado, mas também quem não é alfabetizado, e, nesse sentido, desliga-se de verificar o individual e centraliza-se no social mais amplo (TFOUNI, 1988, apud MORTATTI, 2004, p. 89). (Grifos nossos).

O letramento também é compreendido como um fenômeno mais amplo e que ultrapassa os domínios do ambiente escolar por Kleiman (2008, p. 18). Segundo ela, "podemos definir hoje o letramento como um conjunto de práticas sociais que usam a escrita, como sistema simbólico e como tecnologia, em contextos específicos, para objetivos específicos". O conceito da autora enfatiza os aspectos social e utilitário do letramento.

As práticas específicas da escola, que forneciam o parâmetro de prática social segundo a qual o letramento era definido, e segundo a qual os sujeitos eram classificados ao longo da dicotomia alfabetizado ou não-alfabetizado, passam a ser, em função dessa definição, apenas um tipo de prática - de fato, dominante - que desenvolve alguns tipos de habilidades mas 
não outros, e que determina uma forma de utilizar o conhecimento sobre a escrita (KLEIMAN, 2008, p. 19).

No trecho supracitado, a autora se refere ao fato de que o ambiente escolar, diante da perspectiva do letramento, enfatiza apenas algumas práticas ligadas à escrita e ao uso da escrita. Assim sendo, fora do ambiente escolar outros usos e práticas ligados à escrita são vivenciados. Nesse sentido, Kleiman (2008, p. 20) afirma que o "fenômeno do letramento, então, extrapola o mundo da escrita tal qual ele é concebido pelas instituições que se encarregam de introduzir formalmente os sujeitos no mundo da escrita".

Desta forma, e de acordo com o que já foi exposto anteriormente por esta autora, letramento seria um conjunto de práticas com objetivos específicos e em contextos específicos, que envolvem a escrita. O ambiente escolar, por sua vez, seria apenas uma agência de letramento, dentre várias outras, e realizaria apenas algumas práticas de letramento.

Para Mortatti (2004), o conceito de letramento se liga às funções da língua escrita em sociedades letradas. Segundo esta autora,

Letramento está diretamente relacionado com a língua escrita e seu lugar, suas funções e seus usos nas sociedades letradas, ou, mais especificamente, grafocêntricas, isto é, sociedades organizadas em torno de um sistema de escrita e em que esta, sobretudo por meio do texto escrito e impresso, assume importância central na vida das pessoas e em suas relações com os outros e com o mundo em que vivem (MORTATTI, 2004, p. 98).

Assim, para a autora, em sociedades grafocêntricas, a escrita possui uma importância de proporção muito grande, uma vez que tudo se organiza em torno dela. Diante desse fato, o letramento estaria relacionado aos usos da escrita nessa sociedade grafocêntrica. O letramento também influenciaria a 
relação, não somente dos sujeitos com a sociedade, mas também, com outros sujeitos.

Soares (2009), mesmo apontando a dificuldade de abranger toda a complexidade do significado de letramento em um único conceito, também expressa uma definição para o termo. Segundo ela, letramento pode ser definido como "Resultado da ação de ensinar e aprender as práticas sociais de leitura e escrita; O estado ou condição que adquire um grupo social ou um indivíduo como consequência de ter-se apropriado da escrita e de suas práticas sociais" (SOARES, 2009, p. 39).

Assim letramento está ligado aos usos, às práticas de leitura e de escrita. Além disso, torna-se letrado o indivíduo ou grupo que desenvolve as habilidades não somente de ler e de escrever, mas sim, de utilizar leitura e escrita na sociedade, ou seja, para Soares, somente alfabetizar não garante a formação de sujeitos letrados.

Para a promoção do letramento, é necessário que esses sujeitos tenham oportunidades de vivenciar situações que envolvam a escrita e a leitura e que possam se inserir em um mundo letrado. Conforme Soares (2009, p. 58), em realidades de países como o nosso, o contato com livros, revistas e jornais não é, ainda, algo natural e acessível, portanto, a realidade de alguns contextos de nosso país não contribui para a formação de sujeitos letrados.

\section{Educação antirracista, teoria racial crítica e formação docente}

A Educação Antirracista e a Teoria Racial Crítica fazem parte do rol das abordagens de pesquisas críticas cujo escopo consiste em entender a intrínseca relação entre discurso e práticas sociais. Nesta investigação, isso se aplica mais especificamente à produção e reprodução do poder, ideologia e dominação simbólica e construção de estereótipos relacionados à produção do Outro, segundo Dias (2013). 
Dentre as características de uma educação antirracista que tem por base a teoria racial crítica, elencadas por Ferreira (2006c), achamos pertinentes aqui destacar duas características que consideramos imprescindíveis para escopo desta pesquisa, a saber: a) uma educação nesses moldes vê o racismo como algo endêmico e questiona o papel das instituições na sociedade ao reproduzirem desigualdade com relação à raça e b) desafia a opressão racial e o status quo, que muitas vezes naturaliza desigualdades sociais que fazem com que os negros se sintam diminuídos em sua autoestima e identidade. Dessa forma, o discurso encarrega-se de disseminar e legitimar 'verdades' em relação à construção do Outro. Por isso, nesta investigação, discurso é entendido como um lócus simbólico, responsável pela organização e materialização das relações sociais entre os atores, onde identidades são produzidas hierarquicamente, umas em relação a outras.

No processo educativo, reconhecer as múltiplas interpretações preconceituosas sobre como o outro é construído pelo discurso, nas relações de poder e ideologia e como essas diferenças são usadas como base para a construção de ordem de superioridade, inferioridade, inclusão, exclusão dos atores sociais, de acordo com o nosso entendimento, é um primeiro passo para uma educação mais humana.

Acreditamos fortemente que o conhecimento crítico por parte do professor sobre as múltiplas identidades e sobre as múltiplas realidades que fazem parte da vivência dos discentes fazem com que a sala de aula torne-se um lugar de respeito mútuo, de confiança, uma comunidade que reconhece as similaridades e as diferenças entre os participantes e permite $o$ acolhimento das muitas posições identitárias que habitam aquele lugar.

Dessa forma, os materiais didáticos tornam-se fontes de estudo. Não apenas os materiais didáticos, mas também, as metodologias docentes são colocados sob análise crítica. De acordo com a teoria racial crítica e a educação antirracista, uma perspectiva crítica analisa os gêneros textuais e discursivos, no sentido de trazer à margem o que está, de certa forma, oculto, 
influenciando a mente e, consequentemente, o comportamento dos atores envolvidos no processo de ensinar e aprender.

Assim, achamos pertinentes aqui, levantar algumas considerações que devem ser observadas em todo processo educativo que tem como alvo 0 empoderamento dos atores sociais: a) que tipos de discursos são veiculados nos gêneros textuais? b) eles estão a serviço de quem? c) quem os produziram, onde, quando e para quem? d) como os sujeitos são representados nas imagens que acompanham esses gêneros textuais? e) as identidades de quem são mais proeminentes nesses gêneros? f) com quem elas dialogam ou deixam de dialogar?

Essas são perguntas imprescindíveis, de acordo com o nosso entendimento, para uma pratica docente crítica, pois pode conduzir os alunos a uma tomada de consciência sobre o lugar a eles reservado, predeterminado e, a partir daí, podem, de certa forma, exercer agência humana (NORTON, 2000) em suas interações com o meio social. Conforme afirmam Ferreira (2012, p. 26) e Rajagopalan (2002, p.03), a prática pedagógica que aborda a reflexividade crítica "contribui para a educação dos alunos para que eles possam tornar-se pensadores críticos" desenvolvendo "formas de resistência a injustiças a que são submetidos e, com seus próprios esforços, melhorar as condições de vida e recuperar sua dignidade", respectivamente.

\section{Literatura Infanto-Juvenil e igualdade étnico-racial na Educação Básica}

Em se tratando da literatura voltada para o público infantil e juvenil, ela surgiu no Brasil no final do século XIX e início do século XX, já os personagens negros aparecem no final da década de 1920 e início da década 1930. As histórias, nessa época, mostravam as condições subalternas da personagem negra. Na maioria dessas narrativas, elas não possuíam conhecimento do 
mundo da escrita, considerado erudito, apenas repetiam o que ouviam de outras personagens, como se não tivessem ideias e pensamentos próprios, como elucidado por Sousa (2005).

Ainda, segundo essa autora, a partir das décadas de 1970 e 1980, surge uma Literatura Infanto-Juvenil comprometida com uma representação realista, mas que não por isso deixou de ser preconceituosa, discriminatória e/ou racista. Porém, no final da década de 1980, os livros passaram a apresentar e enfatizar positivamente aspectos da cultura negra como a capoeira e a mitologia dos orixás. São encontradas situações de reflexão sobre a vida e a imagem da personagem negros de maneira positiva e criativa. Pois, é importante ressaltar a

valorização da personagem negra [...] contadora de estórias, que não é estereotipada como a tia Nastácia, mas mantenedora da ancestralidade africana; reforço ao direito à existência e à individualidade das personagens negras [...]; os livros não se remetem somente às crianças brancas, de classe média, como outrora, mas também às crianças negras de diferentes classes e contextos sociais; as personagens femininas negras, na maioria das vezes, deixaram de ser utilizadas apenas como suporte demonstrativo nas histórias que se destinavam a propagar um padrão de vida típico de crianças brancas e de classe média; destacar a contribuição do povo negro na formação econômica e cultural do Brasil; apresentar uma releitura da imagem de passividade da população negra no período escravocrata, bem como o estudo da história e cultura africana; mostrar uma história não oficial sobre os negros no Brasil, a qual deveria ser infimamente conhecida, contada e ensinada nos bancos escolares e pelos diversos meios de comunicação, nossos principais formadores de opinião (SOUSA, 2005, p. 199-200).

Agora, vamos apresentar alguns materiais que podem ser usados nos ambientes escolares para tratar dessas questões. Daremos destaque para alguns livros infanto-juvenis e alguns, especialmente, voltados para professores. 
A editora Língua Geral lançou, em 2007, a coleção Mama África, que apresenta ao público infanto-juvenil brasileiro conto tradicionais da África escritas por autores daquele continente. Todos os livros são ilustrados por artistas plásticos africanos. Compõem a coleção livros com $O$ beijo da palavrinha, escrito por Mia Couto e ilustrado por Malangatana, ambos moçambicanos; O filho do vento, escrito por José Eduardo Agualusa e ilustrado por António Ole, ambos angolanos; Debaixo do arco íris não passa ninguém, escrito pelo angolano Zheto Cunha e ilustrado pelo moçambicano Roberto Chichorro; dentre outros. Os livros oferecem um mergulho muito interessante no universo das lendas africanas.

Apresentamos também a obra $O$ cabelo de cora, de Ana Zarco Câmara e ilustrada por Taline Schubach. Cora é uma menina como as outras, que adora ir à escola e é bastante orgulhosa do seu cabelo. Ele não é liso como os das outras meninas. É enrolado como o de sua Tia Vilma e sua avó. Mas, talvez, o cabelo de Cora não pareça tão para suas colegas e ela pode precisar de um "empurrãozinho" para aprender a amá-lo de novo e a dizer para todo mundo o quanto ele é bonito do jeito que ele é. Cora descobre que seu cabelo é a sua marca. Ela tem cabelo crespo. Outras meninas têm o cabelo liso. Por esse livro é possível nos divertirmos com história de Cora e enxergamos, na diferença, a nossa exclusividade.

Na representação dos indígenas, sugerimos Vozes da floresta: lendas indígenas de Celso Sisto reúne quatro lendas dos povos indígenas: O corpo de Mani, O nascimento da noite, Lua branca em céu de prata e Alagadiélali. Eles apresentam histórias tradicionais como a lenda da mandioca, a lenda do surgimento da noite, a lenda que explica o aparecimento da lua e a lenda que explica porque os animais têm mais ou menos carne. São textos belíssimos, de fazer emocionar.

Na obra Aldeias, palavras e mundos indígenas de Valeria Macedo traz Yana, Ëjcre, Üne, Oo - por incrível que pareça, essas quatro palavras 
significam a mesma coisa, representam, na língua de quatro povos indígenas diferentes (os Yanomami, os Krahô, os Kuikuro e os Guarani Mbya), o vocábulo casa. Através delas e de muitas outras palavras, neste livro o leitor é convidado a conhecer um pouco da vida e dos costumes desses grupos: onde moram, como se adornam, suas festividades, suas línguas, entendendo a diversidade dos povos originários que estão na nossa formação.

Para livros voltados para formação de letramento racial de professores, destacamos África na sala de aula: visita à história contemporânea de Leila Leite Hernandez com prefácio de Mia Couto, este livre reúne aulas de história da África, ministradas entre 1998 e 2003, pela historiadora Leila Leite Hernandez, na PUC de São Paulo. Durante esse período, a autora foi amadurecendo sua visão deste continente tão pouco conhecido e cuja a história é complexa e envolve uma enorme diversidade de culturas e modos de ser.

O livro é bastante didático e funciona como um manual de informações. É voltado para todos aqueles que querem compreender boa parte dos problemas da África contemporânea, e uma excelente obra de consulta para professores das áreas de História, Geografia e Português dente outras do ensino fundamental e médio.

E por último, sugerimos Literatura afro-brasileira: 100 autores de século XVIII ao XXI de Eduardo de Assis Duarte, a proposta deste volume é disponibilizar a professores e estudantes dados biográficos e informações sobre a produção literária de escritores e escritoras afro-brasileiros, enriquecidos com indicações de fontes de consulta. As informações trazidas por este volume ajustam-se ao projeto de valorizar as representações da diversidade étnica brasileira e rejeitar, de forma mais concreta, estereótipos criados sobre a produção literária de negros e negras brasileiros. 


\section{Considerações finais}

Claro que não é só no ambiente escolar público de educação básica que constrói e consolida valores. Há ainda a família, os meios de comunicação, as igrejas, a comunidade e outros espaços de convivência social. Mas não há como negar a importância do ambiente escolar na formação dos aprendentes como cidadãos críticos: na medida em que a aquisição de conhecimento contribui para as pessoas ampliarem sua visão de mundo e entenderem os mecanismos de funcionamento da nossa sociedade, elas se tornam mais aptas a construir com autonomia sua própria vida e interferir na realidade que as cerca.

Parafraseando Rubens Alves, conhecimento que não decifra a vida e não ilumina o mundo não é conhecimento. É enganação. Assim sendo, conhecer as histórias e a culturas africana, afro-brasileira e indígena não é apenas uma obrigação imposta por força de lei. É importante para combater a desigualdade, a discriminação e para compreender verdadeiramente a história e a cultura brasileiras.

Pretendemos, assim, acumular forças para a formação de uma sociedade justa, igualitária e fraterna, livre de toda forma de preconceito, discriminação e opressão, independentemente da cultura, religião, raça e etnia, gênero e orientação sexual. Essas temáticas devem estar presentes de forma transversal em todos os níveis da educação básica pública.

O objetivo desse artigo foi propor um apanhado de livros de literatura infanto-juvenil, de um universo crescente de autores e editores, para contribuir para uma (re)leitura da prática pedagógica, para que essas leis sejam aplicadas e façam sentido no nosso dia a dia, para que a Educação abra novos caminhos para a construção de uma verdadeira cidadania, garantindo o cumprimento da legislação brasileira, que assegura que todos devem ser iguais perante a lei. A ideia foi superar os estereótipos e abordar as temáticas 
indígena e negra mediadas pelas literaturas infanto-juvenil em sua riqueza e diversidade.

\section{REFERÊNCIAS}

ABRAMOVICH, F. Literatura infantil: gostosuras e bobices. São Paulo: Scipione, 1997. (Coleção pensamento e ação no magistério).

AGUIAR, V. T. et al. (Orgs.). Leitura em crise na escola: as alternativas do professor. 2.ed. Porto Alegre: Mercado Aberto, 1982.

ALMEIDA, M. L. P. Como elaborar monografias. 4.ed. rev. atual. Belém: Cejup, 1996.

ARROYO, L. Literatura Infantil Brasileira. São Paulo: Melhoramentos, 1990.

BRASIL. Educação anti-racista: caminhos abertos pela Lei Federal $n^{\circ}$ 10.639/03. Secretaria de Educação Continuada, Alfabetização e Diversidade. Brasília: Ministério da Educação, Secretaria de Educação Continuada, Alfabetização e Diversidade, $2005 . \quad$ Disponível em: $<$ http://www.dominiopublico.gov.br/download/texto/me000376.pdf> Acesso em 31 de agosto de 2015.

COELHO, N. N. Literatura Infantil: Teoria, Análise \& Didática. São Paulo: Moderna, 2000.

. Panorama Histórico da Literatura/ Juvenil: das origens Indo-Européias ao Brasil Contemporâneo. São Paulo: Ática, 2002.

COPE, B.; KALANTZIS, M. Multiliteracies: literacy learning and the design of social futures. Londres: Routledge, 2000.

DIAS, R. S. Desafios enfrentados por alunos de classes sociais menos favorecidas rumo à aprendizagem de inglês: uma questão de identidades. $161 \mathrm{f}$. PPGLA/LET/UnB, 2013. Disponível em: <http://pgla.unb.br/wpcontent/uploads/2013/04/dissertao\%20de $\% 20$ mestrado $\% 20$ \%20\%20romar\%20souza\%20dias.pdf> Acesso em: 15 nov. 2017.

FERREIRA, A. J. Formação de professores raça/etnia: reflexões e sugestões de materiais de ensino em português e inglês. $2^{\mathrm{a}}$ ed., ver. - Cascavel: Assoeste, 2006c. 
- Identidades Sociais de Raça, Etnia, Gênero e Sexualidade: práticas pedagógicas em sala de aula de lígaus e formação de professores/as. Campinas, SP. Pontes Editores, 2012.

GIL, A. C. Como elaborar projetos de pesquisa. $3^{\text {a }}$ Ed. São Paulo: Atlas, 1993.

KATO, M. A. No mundo da escrita: Uma perspectiva psicolinguística. 7 ed. São Paulo: Ática, 2009.

KLEIMAN, A. B. Modelos de letramento e as práticas de alfabetização na escola. Em: . (Org.). Os significados do letramento: uma nova perspectiva sobre a prática social da escrita. Campinas: Mercado das Letras, 2008.

LAJOLO, M. Do mundo da leitura para a leitura do mundo. $6^{\mathrm{a}} \mathrm{Ed} .13^{\mathrm{a}}$ Impressão. São Paulo: Editora Ática, 2008.

.; ZILBERMAN, R. Literatura Infantil Brasileira: História e Histórias. $6^{a}$ Ed. São Paulo: Ática, 1999.

LANKSHEAR, C.; KNOBEL, M. New literacies: changing knowledge and classroom learning. Buckingham: Open University Press, 2003.

LÜKE, A. ; FREEBODY, P. Critical Literacy and the question of normativity : An introduction. In: MUSPRAITT, S.; . Constructing critical literacies: teaching and learning textual practice. Sydney: Allen \&Unwin; andCresskills, NJ: Hampton, pp.1-18, 1997.

MARCONI, M. de A.; LAKATOS, E. M. Técnicas de pesquisa: planejamento e execução de pesquisas, amostragens e técnicas de pesquisa, elaboração, análise e interpretação de dados. $2^{\mathrm{a}}$ Ed. São Paulo: Atlas, 1990.

MARTINS, M. H. O que é leitura. São Paulo: Brasiliense, 2006.

MORTATTI, M. R. L. Educação e Letramento. São Paulo: UNESP, 2004.

NORTON, B. Identity and Language Learning: Gender, Ethnicity and Educational Change. Harlow, England: Pearson Education, 2000.

RAJAGOPALAN, K. O conceito de Identidade em Linguística: é chegada a hora para uma reconsideração radical. In: SIGNORINI, I. (Org.). Língua(gem) e Identidade: elementos para uma discussão no campo aplicado. Campinas, SP: Mercado de Letras, 2002.

ROCHA, C. H. Reflexões e propostas sobre língua estrangeira no ensino fundamental 1: plurilinguismo, multiletramentos e transculturalidade. Campinas, SP: Pontes Editores, 2012. 
ROJO, R. Letramentos múltiplos, escola e inclusão social. São Paulo: Parábola, 2009.

.; MOURA, E. (Orgs.) Multiletramentos na escola. São Paulo: Parábola, 2013.

SILVA, E. D. A carne mais barata do mercado não é a carne negra: atividades na educação básica pública do distrito federal contra o racismo. In: LILIAR cadernos de Pesquisa, s/l. v. 1, n. 1, p. 22-31, 2016. Disponível em: <http://cappuccinopress.com.br/index.php/LiLiAr/article/view/7/8> Acesso em: 15 nov. 2017.

. Eu gosto do gosto de gostar de ler: a leitura como gênero discursivo na escola: In: E-scrita Revista do Curso de Letras da UNIABEU, Nilópolis, v. 6, n. 1, jan./abr, 2015.2 Disponível em: $<$ http://revista.uniabeu.edu.br/index.php/RE/article/view/1624/pdf 368> Acesso em: 15 nov. 2017.

A-TUA-AÇÃO: O texto teatral, o corpo e a voz como mediadores da apropriação da oralidade no ensino-aprendizagem de LE (Francês). $106 f$. PPGLA/LET/UnB, Brasília, 2014. Disponível em: $<$ http://repositorio.unb.br/bitstream/10482/17176/1/2014 EduardoDiasdaSilva.p df> Acesso em: 15 nov. 2017.

SOARES, M. Letramento: um tema em três gêneros. 3 ed. Belo Horizonte: Autêntica, 2009.

SOUSA, A. L. A Representação da personagem feminina negra na Literatura Infanto-Juvenil Brasileira. Em: BRASIL. Educação anti-racista: caminhos abertos pela Lei Federal $n^{\circ}$ 10.639/03. Secretaria de Educação Continuada, Alfabetização e Diversidade. Brasília: Ministério da Educação, Secretaria de Educação Continuada, Alfabetização e Diversidade, 2005. pp. 185-204. Disponível em: $<$ http://www.dominiopublico.gov.br/download/texto/me000376.pdf> Acesso em 31 de agosto de 2015.

STREET, B. Letramentos sociais: abordagens críticas do letramento no desenvo/vimento, na etnografia e na educação. Tradução de Marcos Bagno. São Paulo: Parábola, 2014.

TFOUNI, L. V. Letramento e Alfabetização. 9 ed. São Paulo: Cortez, 2010.

VIEIRA, R. C. Novos rumos para a Linguística Aplicada contemporânea. Em: Revista Eletrônica Odisséia. n. 3. 2009. Disponível em: 
Revista InterteXto / ISSN: 1981-0601

v. 10, n. 2 (2017)

<http://www.periodicos.ufrn.br/odisseia/article/view/2052/1486> acesso em 19 de julho de 2015.

ZILBERMAN, R. A Literatura Infantil na Escola. $11^{\text {a }}$ Ed. São Paulo: Global, 2003.

Artigo recebido em novembro de 2017.

Artigo aceito em abril de 2018. 